\title{
Evaluating Migraine Disability: The Headache Impact Test Instrument in Context
}

\author{
William Pryse-Phillips
}

\begin{abstract}
Migraine impairs physical, social and emotional functioning but the diagnosis is not always made despite the availability of helpful tools. Poor patient-physician communication is one reason cited for this. It is arguable that if the impact that headaches are having on a person's life can be communicated adequately to the physician, the likelihood of appropriate management will increase. The tools currently employed for assessing headache impact are reviewed briefly and the Headache Impact Test (HIT) and HIT-6 described as validated and reliable measures of the effect that headaches are having on patients. The availability of the standard test on the internet, with feedback provided, indicates that this is a potentially useful tool enabling headache sufferers to realize the extent of the burden of migraine and empowering them to seek appropriate management strategies.
\end{abstract}

RÉSUMÉ: Évaluation de l'invalidité due à la migraine: le test d'impact de la céphalée en contexte. La migraine affecte le fonctionnement physique, social et émotif, mais le diagnostic n'est pas toujours fait en dépit de la disponibilité d'outils efficaces. Une des raisons évoquées est une communication médecin-patient déficiente. On peut penser que, si l'impact des céphalées sur la vie d'un patient peut être communiqué adéquatement au médecin, on augmentera les chances d'une prise en charge appropriée. Les outils actuellement utilisés pour évaluer l'impact de la céphalée sont révisés brièvement et le test d'impact de la céphalée (HIT) et le HIT-6 sont décrits comme des mesures validées et fiables pour l'évaluation de l'impact des céphalées chez les patients. La disponibilité sur Internet d'un test standard avec rétroaction indique que c'est un outil potentiellement utile pour faire réaliser aux patients l'ampleur du fardeau de la migraine et les motiver à rechercher des stratégies de gestion appropriées.

Can. J. Neurol. Sci. 2002; 29: Suppl. 2 - S11-S15

Migraine is a chronic disabling disorder, its episodes significantly reducing quality of life ${ }^{1,2}$ and leading to impaired physical, social and emotional functioning both at home and at work. $^{3-6}$ Headache disorders constitute a major public-health problem, impacting both individual sufferers and society. The effects on individuals can be assessed by examining attack frequency, attack duration and headache-related disability. The socio-economic burden includes both direct costs associated with healthcare utilization and costs associated with missed work due to sickness absence or reduced efficiency. Headache disorders deserve more attention, especially concerning strategies leading to adequate primary prevention, diagnosis, and treatment. $^{7}$

It has been estimated (in 1998) that one in four US women aged 30 to 49 suffered from migraine, a condition which in the USA is considered responsible for 112 million bedridden days and $\$ 13$ billion in lost workplace productivity. ${ }^{8}$ Over $40 \%$ of migraineurs who have consulted a physician for headaches reported that the diagnosis of migraine was not made ${ }^{9}$ and although effective and well-tolerated therapies are available, less than half of moderate or severe migraine sufferers are prescribed them. ${ }^{10}$ Among the reasons for the under-diagnosis and undertreatment of migraine, poor patient-physician communication is most frequently cited as a barrier to appropriate care. ${ }^{9,11,12}$ Diagnosis is complicated by the fact that primary care physicians seldom see patients during a migraine attack and must rely on descriptions of symptoms that the patient has experienced remotely.

Studies of consultation in general practice, ${ }^{13,14}$ where migraine patients most often initially consult, ${ }^{8}$ suggest that consultation lengths, which commonly range from 5 - 8 minutes are insufficient for patients adequately to describe their symptoms and the degree of resulting disability. Moreover, such consultations tend to be characterized by physicians providing information to, rather than acquiring information from, patients.

From the Department of Medicine (Neurology), Memorial University of Newfoundland, St. John's NF, Canada

Reprint requests to: William Pryse-Phillips, Professor of Medicine (Neurology), Memorial University of Newfoundland, St. John's NF, Canada A1B 3V6 
In one study of patients with chronic illnesses, ${ }^{14}$ only consultations lasting at least 20 minutes afforded patients an opportunity to raise questions or concerns about their illness and to describe its impact on daily functioning.

A third reason why migraine is under-diagnosed and undertreated may be that many people are reluctant to go to their doctor with complaints about recurrent headaches because they can get relief from over-the-counter medications, or because they perceive physicians to have been somewhat slow in acting upon today's accepted truth that migraine is an organic, debilitating disorder. Migraine subjects who visit their physicians sometimes are treated as though their problem is not of great significance as a casual "stroll" through the various headache chat-rooms on the Internet will demonstrate. Therefore it is necessary to empower migraineurs, for example, by using some tool that will help to explain the degree of disability they suffer on a day-today basis. This should in turn motivate heathcare professionals to accept their complaints at face value.

\section{ToOls for the Assessment of Disability in Migraine}

Numerous tools measuring headache impact have been published, such as the Brief 24-hour Quality of Life Migraine Specific Instrument, Headache Impact Questionnaire (HIMQ) $)^{15,16}$ the Migraine-Specific Quality of Life Questionnaire (MSQ), ${ }^{17,18}$ the SF36, the Medical Outcomes Study Headache Disability Inventory (HDI), ${ }^{19}$ the Sickness Impact Profile (SIP) ${ }^{20}$ and the Migraine Disability Assessment Score (MIDAS). ${ }^{16}$ Of these, the HIMQ, the MSQ, the Short Form (SF-36), and the MIDAS were designed and are commonly used in the assessment of individual patients.

One of the most popular of these scales has been the MIDAS instrument. This five-item questionnaire measures headache- related disability and has the potential to improve doctor-patient communication about the functional consequences of migraine. Its reliability and internal consistency are high, as tested in a population-based sample of headache sufferers as in the case of the HIMQ, ${ }^{16}$ but the MIDAS needs fewer questions, is easier to score, and provides intuitively meaningful information on lost days of activity in three domains. ${ }^{21}$ Migraine Disability Assessment Scores are substantially higher in migraine than in nonmigraine cases, supporting the validity of the measure. ${ }^{22}$ Nevertheless, this scale can be criticized on three grounds. Inability to work must surely be closely correlated with inability to do anything else, including manage a home or family effectively, but here they are treated as separate items. Next, a $50 \%$ reduction in capacity is scored the same as complete inability to perform, which appears illogical. Finally, the nature of the questions is most appropriate for more severely affected subjects.

The $\operatorname{SIP}^{20}$ is another valid and reliable health status measure that has been widely used. It shows good correlations with other health status and functional status measures, but theoretical implications of the construct of sickness, the effect of age and gender on SIP scores, its construct validity as judged by factor analysis, its responsiveness, and the effects of the use of proxyrespondents, of shortening the list and of simplifying the scoring still have to be studied.

However, pain measures alone do not provide enough information about the impact of pain on functioning or quality of life, so measures providing additional information about the impact of pain are coming into use. Holroyd et $\mathrm{al}^{23}$ tried to identify both the dimensions assessed by a set of 22 headacheimpact measures and others that best assessed each of these headache-impact dimensions. Three factors (pain density, disability and affective distress) best accounted for correlations

Table 1. Characteristics of traditional instruments from which the Headache Impact Test item pool was derived

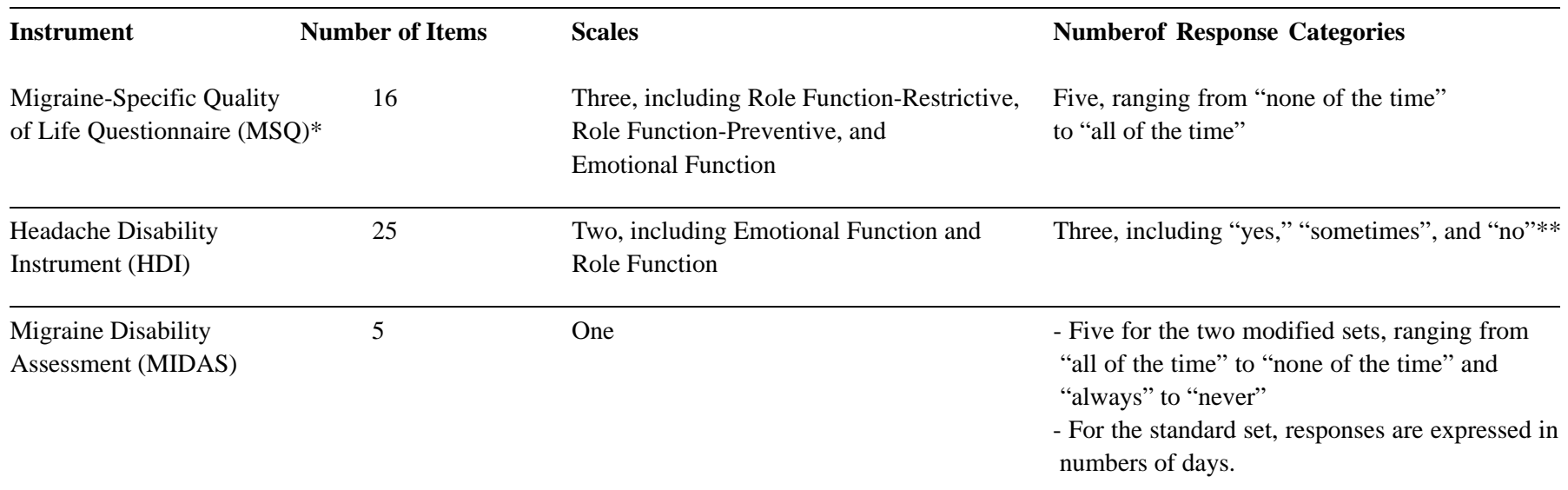

\begin{tabular}{llll}
\hline Headache Impact & 8 & One & Five
\end{tabular}

Questionnaire (HIMQ)

* For the Headache Impact Test item pool, the reference to "migraine" was changed to "headache" on all MSQ items

** The number of response categories was changed to five for the Headache Impact Test item pool. 
among headache-impact measures. An adequate assessment of the impact of recurrent headache disorders in clinical trials and other research may require measures from all three of these headache-impact dimensions.

The self-reported disability of headache sufferers who seek medical assistance (compared with those who do not) differ as a result of perceived disability and psychological factors. Clinic patients report significantly greater disability in their occupation than controls - a difference emerging after controlling for level of headache pain and personality variables. Patients differed from controls, although not significantly, in the rank order of life activities most affected by headache. Discriminant analysis in one study revealed that self-reported disability for occupation and the Hysteria scale from the MMPI- 2 best differentiated the groups. ${ }^{24}$

Subjects with migraine selected from the general population have lower Headache Related Quality of Life as measured by the SF-12 compared with nonmigraine controls. Furthermore, migraine and depression are highly comorbid and each exerts a significant and independent influence on Headache Related Quality of Life. ${ }^{25}$

Migraine can result in work and productivity losses that would be reduced by effective, well-tolerated migraine therapy with rapid onset of relief. The Migraine Work and Productivity Loss Questionnaire was designed to evaluate the impact of migraine and its therapy on paid work. In a short, open-label extension study, 164 migraineurs were randomized to either rizatriptan or their usual migraine therapy. Internal consistency (Cronbach's alpha) for the work difficulty domains ranged from 0.80 to 0.95 . Work loss and work difficulty were moderately correlated with migraine severity and functional ability. Differences were found favoring the triptan for absenteeism (1.3 vs 2.4 hours), effectiveness at work (62\% vs $49 \%)$ and difficulty with work-related tasks. ${ }^{26}$

The HIMQ is a 16-item self-administered questionnaire, including questions about number of headaches in the last three months, headache duration, last headache, pain intensity, need for bedrest, disability in specific domains of activity such as work, household chores and nonwork activity and symptoms. The average pain score and items related to disability (i.e., missed days due to headache, and reduced effectiveness because of headache) in defined activity domains (work for pay, housework, nonwork activities) had the greatest weights on this single factor, supporting prior work on combining measures of pain and disability into a single scale. A score derived as the sum of average pain intensity and total lost time in each of the three domains of activity, expressed as lost days yielded a highly reliable and internally consistent measure of headache severity. ${ }^{9}$

The 24-hour Migraine Quality of Life Questionnaire is a validated migraine-specific questionnaire. In a recent trial, after correcting for multiple comparisons to placebo, rizatriptan $10 \mathrm{mg}$ showed significantly better responses compared to placebo on three of five domains (social functioning, migraine symptoms, and feelings/concerns). ${ }^{27}$

The Medical Outcomes Study SF-36 Health Survey, a generic measure of health status, is also reliable and valid and provides information on a number of health parameters, though not specifically targeted to migraine. ${ }^{28}$ In a Spanish study, this instrument was used to assess the impact of headache on the quality of life among patients with migraine and chronic daily headache $(\mathrm{CDH})$. In this study, $\mathrm{CDH}$ was marked by a lower level of health scales and significantly worse scores on physical functioning, role functioning (physical), bodily pain, general health perceptions and mental health than patients with migraine. Other data suggest that the SF-36 questionnaire is valuable in determining the differences in functional status among patients with migraine and other headache types ${ }^{1}$ and that the SF-36 is a reliable and valid measure of the quality of life of patients with $\mathrm{CDH}$. It may also prove to be valuable in studying the efficacy of therapeutic agents for this type of headache. ${ }^{29}$

\section{A New Tool: The Headache Impact Test}

From the SF-36, Ware ${ }^{30}$ constructed the Headache Impact Test (HIT), a scale that differs from the others in that it measures a wider range of levels of disability and impact. The HIT comes in two formats, each asking questions specific to six areas in which headache might affect an individual's ability to function, such as pain, daily/social activities and energy/fatigue. The item pool for the test comprised all items from four previously validated, traditional headache disability instruments, including the MSQ, the HDI, MIDAS, and the HIMQ.

Using item-response theory, ${ }^{31}$ calibration of HIT items yielded an instrument that provides a score indicative of a patient's status with respect to a unidimensional concept of headache disability. This ability distinguishes this from other headache disability instruments such as the HDI and the MSQ, each of which represents headache impact multidimensionally. The strong correlations ( 0.51 to 0.87 ) between HIT scores and scale score estimates of traditional headache disability instruments support the validity of the test as a measure of headache disability.

The HIT battery consists of 53 items, taken either from four previously-accepted measures of headache impact, namely the MSQ, Headache Disability Index, MIDAS and HIMQ or newly derived. The test was constructed after analyses of the responses of over 1000 US subjects with headaches. These analyses included initial factor analysis, later use of Item Response Theory statistical methodology and ultimately pilot testing through the Internet in over 10,000 subjects accessing the site at http://www.headachetest.com. ${ }^{30}$ As a result, the test now normally requires five or fewer questions to allow a reliable estimate of a subject's score, the confidence intervals being set at 5 to 15 for severe and less severe impact, respectively.

On taking the test, a person answers the first (standard) question and on the basis of the reply, a tentative score is assigned within the computer program. The next question is selected from another that is appropriate for a person with that level of disability; if the answer indicates a consistent response pattern, a third and further questions may or may not be required to achieve the narrow prespecified confidence limits set. The level of disability is then expressed as a figure around an arbitrary mean of 50, this mean reflecting the average disability suffered by members of a headache population.

The printout offered by the programme when the test is taken on the internet supplies this score with a comment about its meaningfulness in comparison to other members of the headache population of North America, and also offers advice about the 
Table 2: The Six-Item (paper-based) Headache Impact Test, with Annotations

Answers are forced-choice; Never, Rarely, Sometimes, Very Often, Always. In the following notes, the order of the questions in the HIT-6 has been changed.

1. When you have headaches, how often is the pain severe? The HIT does not assess nausea/vomiting, photo-phono-phobia or malaise

2. When you have a headache, how often do you wish you could lie down?

3. How often do headaches limit your ability to do usual daily activities including household work, work, school, or social activities?

This question refers to impact and properly combines home, school and social activities

4. In the past 4 weeks, how often did headaches limit your ability to concentrate on work or daily activities?

The last 4 weeks is the right time frame, as patients will probably remember this time period rather than three months

5. In the past 4 weeks, how often have you felt too tired to do work or daily activities because of your headaches?

6. In the past 4 weeks, how often have you felt fed up or irritated because of yourheadaches?

This question looks at the emotional ['Role Emotion'] aspect.

Symptoms other than Pain, Mental Health and Concerns/Health Perceptions are not subjects of questions for the HIT-6.

next steps that a headache sufferer might wish to take given his/her impact level, and a note on the score and its clinical significance that can be presented to the subject's personal physician.

A paper-based version ${ }^{32,33}$ for individual usage, (Table 2) providing a score only without recommendations, is also available and has been validated with reference to the original HIT instrument. ${ }^{34,35}$

\section{CONCLusions}

Determination of the need for treatment of headache appears to be predicated by a physician's awareness of the degree of disability that the headache syndrome is causing. Instruments to facilitate such insights are therefore required and the HIT instrument appears today to be highly appropriate for this purpose on account of its ease of access through the internet or as a short six-item printed questionnaire; the range of headache impact levels that it comprehends, and the supporting information that is delivered with the test results. The method of delivery of the test is innovative; since it is most commonly taken on the internet from the security of the subject's home, external pressures are unlikely to apply. The HIT would seem to be a valuable new instrument for the assessment of the burden of headache upon migraineurs.

\section{ACKNOWLEDGEMENT}

Dr William Pryse-Phillips is medical advisor (CNS) to GlaxoSmithKline, the sponsors of the Headache Impact Test.

\section{REFERENCES}

1. Terwindt GM, Ferrari MD, Tijhuis M, et al. The impact of migraine on quality of life in the general population. The GEM study. Neurology 2000;55:624-629.

2. Dowson A, Jagger S. The UK migraine patient survey: quality of life and treatment. Curr Med Res Opin 1999;15:241-253.

3. Tulen JH, Stronks DL, Bussmann J, et al. Towards an objective quantitative assessment of daily functioning in migraine: a feasibility study. Pain 2000;86:139-149.

4. Osterhaus, JT, Townsend RJ, Gandek B, Ware JE Jr. Measuring the functional status and well-being of patients with migraine headache. Headache 1994;34(6):337-343.

5. Von Korff M, Stewart WF, Simon D, Lipton RB. Migraine and reduced work performance. Neurology 1998;50:1741-1745.

6. Miller DW, Martin BC, Loo CM. Sumatriptan and lost productivity time; a time series analysis of diary data. Clin Ther 1996;18: $1263-1275$.

7. Rasmussen BK. Epidemiology and socio-economic impact of headache. Cephalalgia 1999;19 (Suppl 25):20-23.

8. Hu XU, Markson LE, Lipton RB, Stewart WF, Berger ML. Burden of migraine in the United States: disability and economic costs. Arch Intern Med 1999;159:813-818.

9. Stewart WF, Lipton RB, Von Korff M, Liberman J. Reliability of an illness severity measure for headache in a population sample of migraine sufferers. Cephalalgia 1998;18:44-51.

10. Stewart WF, Lipton RB. Migraine Headache; epidemiology and health care utilization. Cephalalgia 1993;13 (Suppl 12):41-46.

11. Blau JN, MacGregor EA. Migraine consultations. A triangle of viewpoints. Headache 1995;35:104-106.

12. MacGregor EA. The doctor and the migraine patient; improving compliance. Neurology 1997;48:S16-S20.

13. Carr-Hill R, Jenkins-Clarke S, Dixon P, et al. Do Minutes Count? Consultation lengths in General Practice. J Health Serv Res Policy 1998;3:207-213.

14. Martin CM, Banwell CL, Broom DH, et al. Consultation length and chronic illness care in general practice. Med J Aust 1999;171:77-81.

15. Stewart WF, Lipton RB, Simon D, Liberman J, Von Korff M. Validity of an illness severity measure for headache in a population sample of migraine sufferers. Pain 1999;79:291-301.

16. Stewart WF, Lipton RB, Kolodner K, Liberman J, Sawyer J. Reliability of the migraine disability assessment score in a population-based sample of headache sufferers. Cephalalgia 1999;19:107-114.

17. Jhingran P, Osterhaus JT, Miller DW, et al. Development and validation of the Migraine-Specific Quality of Life Questionnaire. Headache 1998;38:295-302.

18. Jhingran P, Davis SM, LaVange LM, et al. Migraine specific quality of life questionnaire: Further investigation of the factor structure. Pharmacoeconomics 1998;13:707-717.

19. Jacobson GP, Ramadan NM, Norris L, et al. Headache Disability Inventory: short-term test-retest reliability and spouse perceptions. Headache 1995;35:534-539.

20. de Bruin AF, de Witte LP, Stevens F, Diederiks JP. Sickness Impact Profile: the state of the art of a generic functional status measure. Soc Sci Med 1992;35:1003-1014.

21. Stewart WF, Lipton RB, Whyte J, et al. An international study to assess reliability of the Migraine Disability Assessment (MIDAS) score. Neurology 1999;53:988-994. 
22. Stewart WF. Reliability of the migraine disability assessment score in a population-based sample of headache sufferers. Cephalalgia 1999;19:107-114.

23. Holroyd KA, Malinoski P, Davis MK, Lipchik GL. The three dimensions of headache impact: pain, disability and affective distress. Pain 1999;83:571-578.

24. Ziegler DK, Paolo AM. Self-reported disability due to headache: a comparison of clinic patients and controls. Headache 1996;36: 476-480.

25. Lipton RB, Hamelsky SW, Kolodner K, Stewart WF. Migraine, quality of life and depression: a population-based case-control study. Neurology 2001;55:629-635.

26. Davies P. Therapy for Alzheimer's disease: choosing a target. Clin Neuropharmacol 1991;14 (Suppl 1):S24-S33.

27. Santanello NC, Polis AB, Hartmaier SL, et al. Improvement in migraine-specific quality of life in a clinical trial of rizatriptan. Cephalalgia 1997;17:867-872.

28. Ware JE, Gandek B. Overview of the SF-36 Health Survey and the International Quality of Life Assessment. J Clin Epidemiol 1998;51:903-912.

29. Monzon MJ, Lainez MJ. Quality of Life in migraine and chronic daily headache patients. Cephalalgia 1998;18(9):638-643.
30. Ware JE, Bjorner JB, Kosinski M. Practical implications of item response theory and computerized adaptive testing: a brief summary of ongoing studies of widely used headache impact scales. Med Care 2000;38:1173-1182.

31. Cella DF, Chang CH. A discussion of item response theory and its applications in health status assessment. Med Care 2000;38: 1166-1172.

32. Kosinski M, Bjorner JB, Dahlof C, et al. Development of HIT-6, a paper-based short form for measuring headache impact. American Headache Assoc. Annual Meeting. New York, June 2001.

33. Bayliss MS, Kosinski M, Diamond M, et al. HIT-6 scores discriminate between headache sufferers differing in headacheassociated workplace productivity loss. American Headache Assoc. Annual Meeting. New York, June 2001.

34. Garber WH, Kosinski M, Dahlof C, et al. HIT-6 reliably measures the impact of headache. American Headache Assoc. Annual Meeting. New York, June 2001.

35. Ware J, Kosinski M, Dahlof C, et al. Validity of HIT-6, a paperbased short form for measuring headache impact. American Headache Assoc. Annual Meeting. New York, June 2001. 